\title{
A New Species of Mayfly, Maccaffertium annae sp. nov. (Ephemeroptera: Heptageniidae) from Mexican Amber (Miocene)
}

\author{
Craig R. Macadam ${ }^{1, *}$, Andrew J. Ross ${ }^{2}$ \\ ${ }^{1}$ Buglife - The Invertebrate Conservation Trust, Balallan House, 24 Allan Park, Stirling, FK8 2QG, Scotland, UK. \\ ${ }^{2}$ National Museum of Scotland, Chambers Street, Edinburgh, EH1 1JF, Scotland, UK. \\ *craig.macadam@buglife.org.uk
}

\begin{abstract}
Maccaffertium annae sp. $\mathrm{n}$. is described in the Mexican amber of early Miocene age. It constitutes the first species of mayfly (Ephemeroptera), the first record of the family Heptageniidae to be described from this amber, and also the first fossil record of the genus Maccaffertium. The species is represented by male and female imagos in one piece of amber.
\end{abstract}

Keywords: Amber, Ephemeroptera, Maccaffertium, Miocene, Mexico.

Resumen

Maccaffertium annae sp. $n$. se describe en el ámbar mexicano del Mioceno temprano. Constituye la primera especie de efimera (Ephemeroptera), el primer registro de la familia Heptageniidae que se ha descrito de este ámbar, y el primer registro fósil del género Maccaffertium. La especie está representada por imagos masculinos y femeninos en una pieza de ámbar.

Palabras clave: Ámbar, Ephemeroptera, Maccaffertium, Mioceno, México.

\section{Introduction}

Mexican amber is one of the major types of fossiliferous ambers in the world and has yielded about 200 families of arthropods so far. Most of the amber has been extracted from Simojovel in Chiapas State. The resin was produced by the legume tree Hymenaea mexicana which grew in a forest close to a mangrove swamp (Solórzano-Kraemer, 2010). The amber is considered to be about $15-20$ million years old which corresponds to the Burdigalian stage of the Miocene (International Chronostratigraphic Chart v2014/02 www.stratigraphy.org).

Mayflies (Ephemeroptera) are well known from the fossil record with more than 200 species having been described. However, they are comparatively rare in amber with 46 species described in amber from: the Baltic (31 species); New Jersey (5); Dominican Republic (4); Burma (3); Russia (2); and China (1). Their rarity is not surprising given that they spend most of their life cycle as nymphs in streams or other freshwater habitats. The adults (imagos) live from a few hours to a few days. Imago mayflies have no attraction to resin, though may use trees as somewhere to rest. For them to get trapped in sticky resin is purely by accident.

Three families of mayflies have been recorded from Mexican amber so far (Baetidae, Leptohyphidae and Leptophlebiidae in Solórzano-Kraemer, 2010) however no species has hitherto been described and named. The species described here constitutes the first species of mayfly to be named and the first record of the family Heptageniidae in Mexican amber. The new species is based on a male and a female imago in the same piece of amber (Figure 1) 


\section{Systematic Paleontology}

Order: Ephemeroptera Hyatt \& Arms, 1890

Family: Heptageniidae Needham, 1901

Genus: Maccaffertium Bednarik, 1979

Type species. Maccaffertium mexicanum Ulmer, 1920

\section{Maccaffertium annae sp. $\mathrm{n}$.}

Holotype. NMS G.2008.34.3.1 (Figures 1-3) imago male in a piece of Mexican amber, nearly complete though missing half of the left fore-wing, most of the length of the caudal filaments (cerci) and tips of left fore-leg, mid-leg, and both hind-legs. The right fore-leg is detached. Some parts such as the eyes, thorax and abdomen shrunken. Housed in the National Museums Collection Centre, National Museums Scotland, Edinburgh, purchased from Roland Torikian.

Paratype. NMS G.2008.34.3.2 (Figure 1) imago female in the same piece of amber as the holotype, complete imago just missing the tips of its left fore- and mid-legs, and entire left hind-leg. The similarity of fore-wing venation and that the imagos were trapped at the same time (during swarming) indicate that this specimen is conspecific with the holotype.

Type locality. Simojovel, Chiapas State, Mexico.

Type age. Burdigalian (Miocene).

Etymology. The specific epithet is named after Ann Ross, daughter of AJR.

Diagnosis. This species belongs to the Heptageniidae based on the presence of two pairs of intercalary veins in the cubital field of the fore-wing - the shorter pair adjacent to $\mathrm{Cu} 1$, and five tarsal segments in the fore-leg. This species was placed in the genus Maccaffertium based on its forewing venation and the morphology of the penes, the latter bearing a superficial resemblance to those of the type species M. mexicanum Ulmer. It differs from other species in this genus by the following combination of characters: fore-wing cross-veins reduced, pigmented in the Radial and Medial fields; arranged in four transverse bands; penis lobes subquadrate, divergent, split to base.

Description. Male imago. Measurements: Length from tip of head to tip of abdomen (excl. genitalia) - $5.3 \mathrm{~mm}$; fore-wing length $-5.8 \mathrm{~mm}$; fore-wing width $-2.0 \mathrm{~mm}$; hind-wing length $-2.0 \mathrm{~mm}$; hind-wing width $-1.1 \mathrm{~mm}$.

Abdomen $3.1 \mathrm{~mm}$ long; 10th abdominal segment with two pairs of small projections at the posterior corners near bases of caudal filaments and forceps.

Head with compound eyes large and separated by 0.3 $\mathrm{mm}$ dorsally, antennae longer than the head.

Fore-wing hyaline (Figure 2), venation (nomenclature based on Elliott and Humpesch, 1983) typical of Heptageniidae: $\mathrm{C}, \mathrm{Sc}$ and $\mathrm{R}$ dark, run straight to mid-wing then gently curve; Sc and R very close in basal half, then diverge; RS with 4 pale main veins (R2, R3, R4, R5), R2 and R3 branch at basal quarter of wing with 5 intercalaries; R4 and R5 branch at mid-wing with one intercalary. M1 and M2 pale, branch at basal quarter of the wing with one intercalary; $\mathrm{Cu} 1$ and $\mathrm{Cu} 2$ pale and simple, diverge with two pairs of intercalaries, the shorter pair adjacent to $\mathrm{Cu} 1$; A1 pale with 3 intercalaries between A1 and wing margin.

Cross-veins reduced, pigmented in the Radial and Medial fields; arranged in four transverse bands, the basal band not contiguous and less distinct. Costal area with 11 cross veins, proximal four cross-veins and costal brace strongly pigmented in surrounding membrane; pterostigmatic area with seven simple, not anastomosed, veins.

Hind-wings with slight costal projection present; Sc sigmoidal in basal third diverging from stem of $\mathrm{R}$ then running parallel to $\mathrm{C}$, gently curving posteriorly; $\mathrm{R} 1$ almost straight, curved gently at wing-tip; R2 and R3 floating (not joined) with one intercalary; R4+R5 branching from R1 at basal third; R4 and R5 branching almost at distal third of wing, with one intercalary; M1 and M2 simple and diverge with 2 intercalaries; $\mathrm{Cu} 1$ and $\mathrm{Cu} 2$ parallel, with two intercalaries between $\mathrm{M} 2$ and $\mathrm{Cu} 1$; $\mathrm{A} 1$ short, floating and indistinct. The left hind-wing appears to have a colour band but this is a taphonomic artefact, not original pigmentation.

Fore-leg (Figure 3): femur $1.8 \mathrm{~mm}$ long; tibia $2.2 \mathrm{~mm}$ long; tarsal claws dissimilar, with one pointed and one blunt claw on each leg; 5 tarsal segments, $2-4$ very long, 1 and 5 short, segment 1 length $0.2 \mathrm{~mm}$, segments 2 and 3 length $1.0 \mathrm{~mm}$, segment 4 length $0.8 \mathrm{~mm}$, segment 5 length 0.3 $\mathrm{mm}$. Mid-leg: femur $1.6 \mathrm{~mm}$; tibia $1.5 \mathrm{~mm}$; tarsal segments difficult to see due to the amber, however they are all very short; 2 distinct sharp claws. Hind-leg femur $1.4-1.5 \mathrm{~mm}$; tibia $1.4 \mathrm{~mm}$, tarsal segment 1 length $0.1 \mathrm{~mm}$, segments 2 and 3 length $0.2 \mathrm{~mm}$, end of leg not present.

Forceps base elongated with small spine apically; forceps three-segmented, segments 1 and 2 with slight projections apically, segment 1 length $0.5 \mathrm{~mm}$, segment 2 and 3 length $0.1 \mathrm{~mm}$. Penis lobes sub-quadrate, divergent, split to base (Figure 4). Caudal filaments, basal $3 \mathrm{~mm}$ of left filament present.

Female imago. Length from tip of head to tip of abdomen $4.9 \mathrm{~mm}$. Fore-wing length $6.2 \mathrm{~mm}$, width $2.1 \mathrm{~mm}$; hind-wing curled so not possible to measure.

Abdomen length $2.8 \mathrm{~mm}$, broad, with the remains of some eggs.

Fore-wing venation similar to male except one extra cross-vein in pterostigmatic area and an extra 'band' of cross-veins at wing-tip.

Legs at angles that make measurement difficult. Foreleg tarsi with segments 1 and 5 shorter than $2-4$. All three legs have dissimilar claws with one pointed, one blunt.

Length of caudal filaments $-13.6 \mathrm{~mm}$, annulated, but flattened for much of the length.

Male and female subimagos and nymphs are unknown.

In the same piece of amber is a fulgoroid bug (Hemiptera: Fulgoroidea), spider (Arachnida: Araneae), 2 male and female chironomid midges (Diptera: Chironomidae), 2 parasitic 


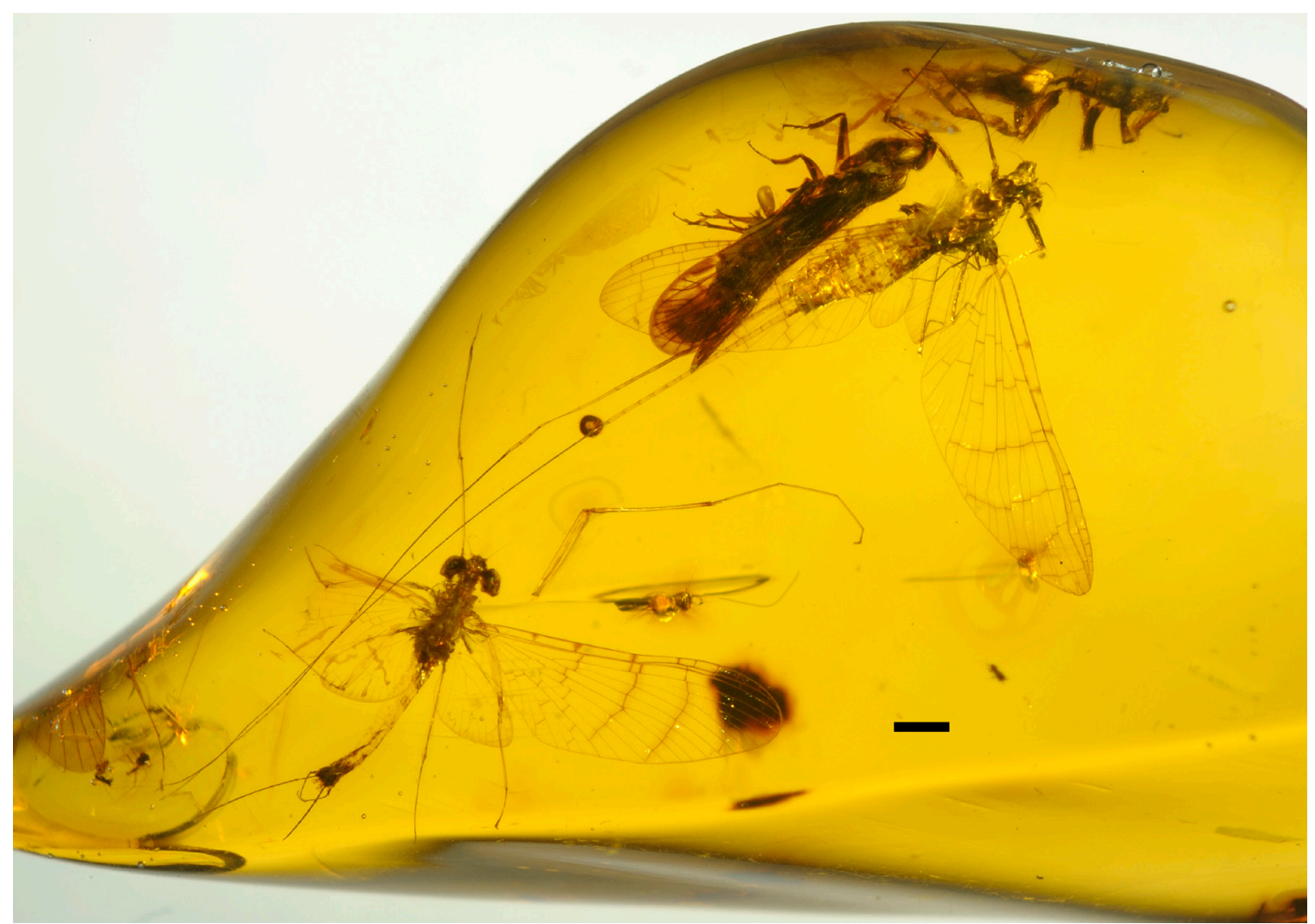

Figure 1. Overview of the Mexican amber piece NMS G.2008.34.3 showing inclusions- bottom left, male imago holotype of Maccaffertium annae sp. nov.; top right female imago paratype, partially overlain by a fulgoroid bug.

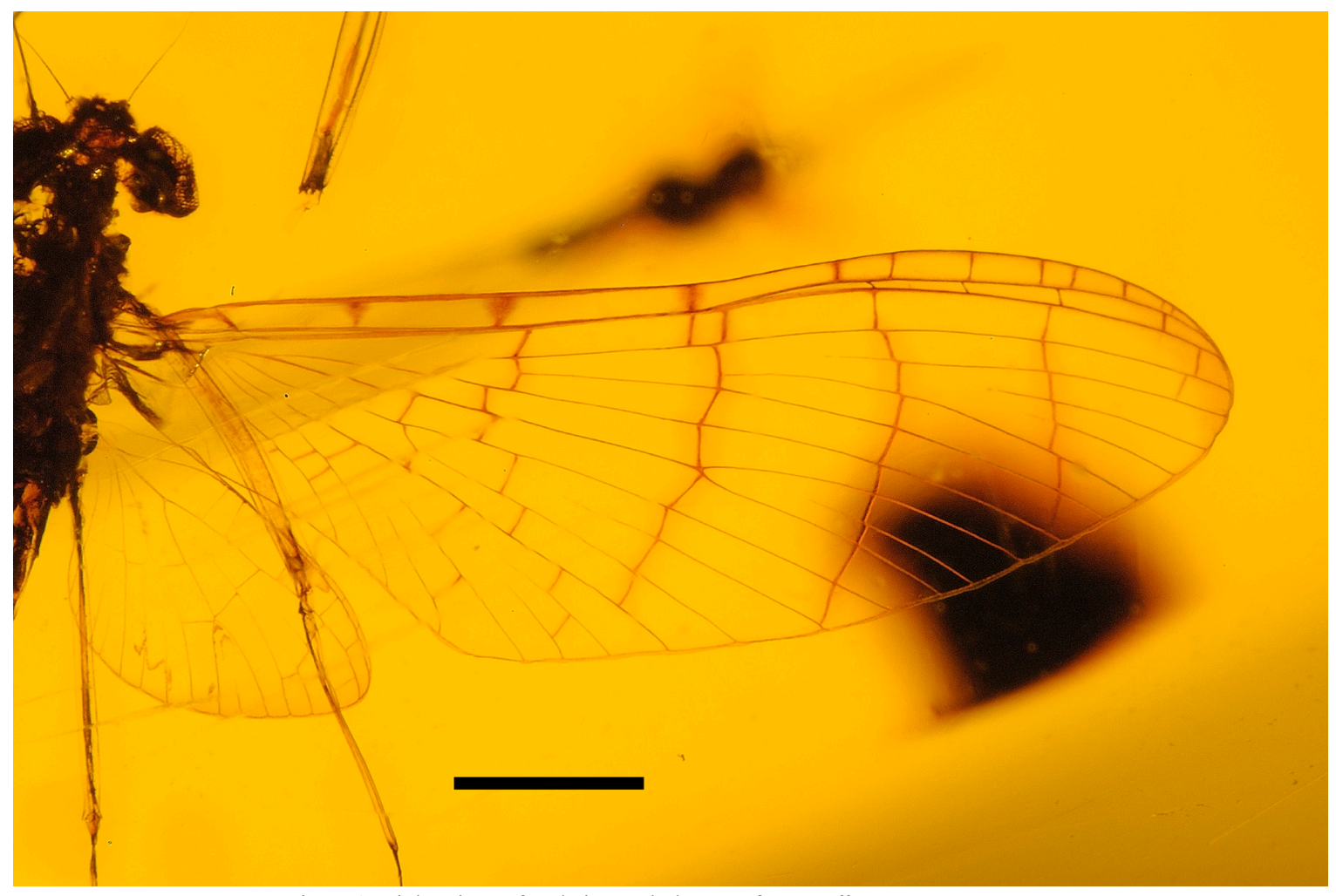

Figure 2. Right wings of male imago holotype of Maccaffertium annae sp. nov. 


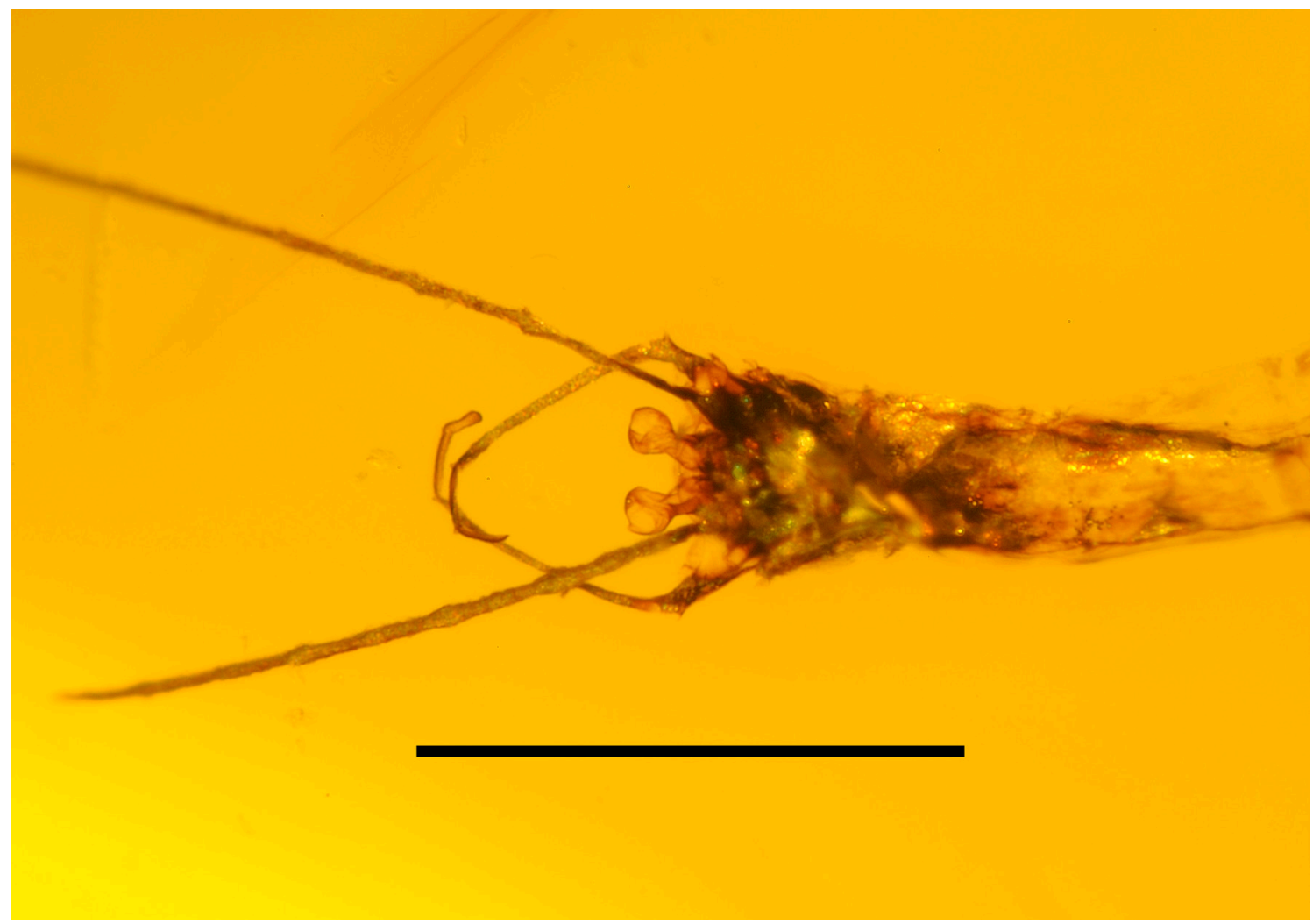

Figure 3. Dorsal view of genitalia of male imago holotype of Maccaffertium annae sp. nov.

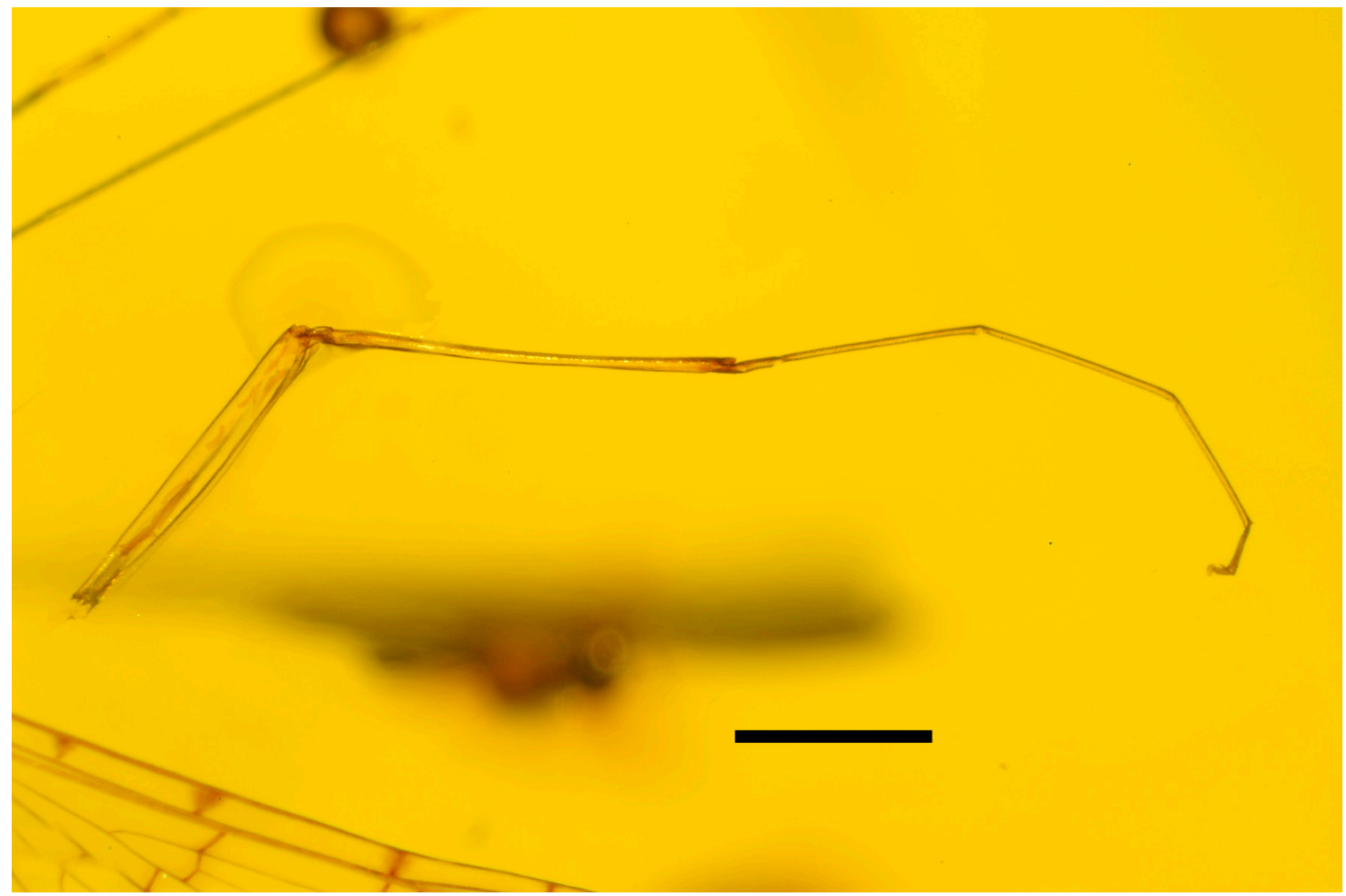

Figure 4. Right fore-leg of male imago holotype of Maccaffertium annae sp. nov. 
wasps (Hymenoptera: Parasitica, incl. Chalcidoidea), male coccoid (Hemiptera: Coccoidea) and wing tips and legs of a caddisfly (Trichoptera).

\section{Discussion}

Over 150 extant species of mayfly are known from Mexico (Mayfly Central, 2014, www.entm.purdue.edu/ mayfly [accessed 15th October 2014]). The Heptageniidae are represented by 12 species, however Maccaffertium annae sp. $\mathrm{n}$. is the first fossil Heptageniidae species recorded from Mexican amber.

The genus Maccaffertium comprises 19 species. Maccaffertium annae sp. $n$. can be distinguished from other known species of the genus by the following combination of characters: fore-wing cross-veins reduced, pigmented in the Radial and Medial fields; arranged in four transverse bands; penis lobes sub-quadrate, divergent, split to base. The penes and fore-wing venation of M. annae superficially resemble those of the type species Maccaffertium mexicanum (Ulmer, 1920) (figured as Stenonema integrum) in Bednarik and McCafferty (1979). The penes are however more slender and elongated and the fore-wing venation is greatly reduced, much more so than M. mexicanum.

Bednarik and McCafferty (1979) suggest that the genus Maccaffertium originated in the Appalachian Mountains of eastern North America. They further suggest that the genus dates from the Pleistocene era. Maccaffertium mexicanum (Ulmer, 1920) is the only member of the genus known from Mexico. Two sub-species of M. mexicanum are recognised: M. mexicanum mexicanum (Ulmer, 1920) and M. mexicanum integrum (McDunnough, 1924), both of which are known from Mexico. Bednarik and McCafferty (1979) suggest that these populations originated from eastern Texas stock however the discovery of M. annae from Miocene deposits in southern Mexico disproves this theory.

The male and female imagos in one piece of amber indicate that the particular tree that produced this blob of resin was probably growing close to a running water-source where the mayflies were swarming. Both imagos have their wings outstretched indicating that they were flying when they became stuck. It is tempting to suggest that the individuals were mating, or had recently mated, in which case the abdomen of the female would still be filled with eggs, however as only some eggs are present this suggests she had already laid some before getting trapped.

\section{Acknowledgements}

Many thanks to Bill Crighton (NMS volunteer) for taking the photographs and Noelia Collado Salas for assistance with Spanish translation.

\section{References}

Bednarik, A.F., McCafferty, W.P., 1979, Biosystematic revision of the genus Stenonema (Ephemeroptera: Heptageniidae): Canadian Bulletin of Fisheries and Aquatic Sciences, 201, 1-73.

Elliott, J.M., Humpesch, U.H., 1983, A Key to the Adults of the British Ephemeroptera with notes on their ecology, Scientific Publication No. 47, Freshwater Biological Association, 1-101.

Solórzano-Kraemer, M.M., 2010, Mexican amber, in Penney, D. (ed.), Biodiversity of fossils in amber from the major world deposits, Siri Scientific Press, Rochdale, 42-56.

Manuscript received: October 10, 2014

Corrected manuscript received: February 20, 2015

Manuscript accepted: February 27, 2015 